\title{
A noninvasive, continuous brain monitoring method: rheoencephalography (REG)
}

\author{
Michael Bodo' ${ }^{1,2 *}$ \\ ${ }^{1}$ Ochsner Medical Center, New Orleans, LA, USA \\ ${ }^{2}$ Uniformed Services University of the Health Sciences, Bethesda, MD, USA \\ *Correspondence: michaelbodo1947@gmail.com \\ In memoriam Yuri Yevgenevich Moskalenko
}

Competing interests: Author(s) stated no compete of interest.

Grant information: Dama Research Center limited supported this study.

Copyright 2020 (C) The Author(s). This is an Open Access article under the CC-BY 4.0 license published by Dama Research Center limited a private company limited by shares organized and existing under the laws of Hong Kong, with its head office located at Room 409, Beverley Commercial Centre, 87-105 Chatham Road South, Tsim Sha Tsui, Kowloon- Hong Kong and company number: 2875213.

How to cite: Bodó, M. "A noninvasive, continuous brain monitoring method: rheoencephalography (REG)" DRC Sustainable Future 2020. 1(2): 94-110. DOI: $10.37281 / \mathrm{DRCSF} /$

\section{ABSTRACT}

This paper deals with the sustainability under anoxic conditions of human beings, both when healthy, and diseased. As our attention is focused these days on the environment, sustainability, and green energy, a similar effort is being made in neuromonitoring to switch from invasive to noninvasive monitoring methods. Keys to these changes are computerization and shrinking size of electronic hardware. Computerization is going on in all areas of biomedical engineering, both in research and in clinical fields of medicine. In neurology, brain imaging is the most characteristic change in recent decades. These modalities of imaging (MRI, CT, PET scan, etc.) are predominantly utilized for localizing brain pathology. Brain imaging offers great spatial resolution, but poor time resolution. Therefore, for continuous monitoring, neurocritical care departments require an additional tool with good time resolution. There are invasive and noninvasive neuromonitoring methods. The standard method to monitor intracranial pressure (ICP) is an invasive method. Computerization allows for calculating the cerebral blood flow autoregulation (CBF AR) index (pressure reactivity index - PRx) from ICP and systemic arterial pressure (SAP) in real time, continuously, but invasively. The new development, discussed in this paper, is to calculate this index noninvasively by using rheoencephalography (REG), called REGx. We present the road to this invention and summarize multifold REG related results, such as using REG for primary stroke prevention screening, comparison incidence of arteriosclerotic risk factors, various studies by using CBF manipulations, and correlations with other neuromonitoring methods, and validation with in vitro and in vivo methods. REG by using different algorithms allow for real time calculation of autoregulated blood flow. This paper presents results of validation of CBF algorithms as an effective, noninvasive method. The author's intent is to supply sufficient physiological background information. This review covers the author's research efforts over several decades; it pertains multiple studies and has an updated addition to human sustainability by considering that Covid-19 is increasing stroke and cardiovascular disease (CVD) morbidity and mortality.

Keywords: Brain monitoring, REG, Rheoencephalography, Neuromonitoring, MRI, CT, PET 


\section{Introduction}

The first published studies of bioimpedance measurements of brain circulation, in the 1950s, show a trajectory like early measurements of heart and brain electrical activity (electrocardiogram ECG and electroencephalogram - EEG). Early bioimpedance research (Nyboer, 1954; Kubicek et al., 1975) began with thoracic (cardiac) measurements, which were soon followed by measurements of brain circulation (Nyboer, 1960, 1070; Lifshitz, 1963, Geddes et al., 1964, Yarullin, 1965, Polzer and Schuhfried, 1962). The original bioimpedance device was a four-electrode system (Kubicek et al., 1974; Patterson, 1995), later modified to two electrodes (Markovich et al., 1967, Seipel, 1967, Namon, et al., 1967). The electrical impedance method (measuring blood flow by alternating current) is known in clinical practice; however, it is used primarily in cardiology to determine cardiac output (ICM) and peripheral circulation (venous occlusion plethysmography). Electrical impedance plethysmography measured on the head is called cephalography or REG. The United States Food and Drug Administration (US FDA) definition states: A rheoencephalograph is a device used to estimate a patient's cerebral circulation (blood flow in the brain) by electrical impedance methods with direct electrical connections to the scalp or neck area. (Anonymous 1). PubMed search with keyword Rheoencephalography found 312 hits (Anonymous 2). Bioimpedance amplifiers use a two-stage Wheatstone bridge-differential amplifier circuit design (Anonymous 3). Frequency is measured is in the range from $15 \mathrm{kHz}$ to $1 \mathrm{mHz}$ (Moskalenko, 1980, Jenkner, 1986, Meghdadi et al., 2019). REG is based on monitoring pulse synchronous variations in cranial electrical impedance over time.

Two-electrode system can record pulsatile component only, which is a small portion of total impedance. The advantage of four-electrode system is that it can measure basic impedance; it is used for cardiac output (thoracic bioimpedance ICG) and peripheral circulation measurements. Significant physiological information derived from the REG signal relates to fluid content, vasoconstriction, and vasodilation in the brain. This is manifested by decreasing and increasing REG pulse amplitudes, respectively. The units of these amplitude changes are measured in Ohms, however, there are no normative values associated with the REG amplitude values due to the many factors that can affect it, detailed by Moskalenko (1980). The electrical impedance/REG pulse curve looks like an inverted arterial pressure pulse curve. REG pulse wave amplitude is due to the conductivity differences between brain tissue, cerebrospinal fluid, and blood. Blood and cerebrospinal fluid are better conductors than the brain and other 'dry' tissues. Various correlations have been established between REG and cerebral blood flow (CBF) (volume, flow, or pressure, detailed by Jenkner, 1986, Eniya, 1973, Naumenko and Skotnikov, 1975). Consensus from a review of published REG literature is that the REG signal represents volume change. It was demonstrated that REG signal reflects information of cerebrovascular reactivity, intracranial pressure, arteriosclerotic change of brain vessels (McHenry, 1965, Jenkner, 1970). REG pulse amplitude is quantified most frequently by using its derivative (Jacquy et al., 1974, Hadjiev, 1968) or integral. Both variables are sensitive to changes in $\mathrm{CBF}$ induced by perturbations such as $\mathrm{CO} 2$ inhalation, Trendelenburg position, carotid occlusion, breath holding, Valsalva maneuver, and hemorrhage. Earlier studies (Moskalenko, 1980) made an initial effort to establish pathophysiological correlates to REG (McHenry, 1965, Jenkner, 1986), but did not establish a correlation between arteriolar/venular blood volume and CBF autoregulation (AR). The correlation of REG anacrotic (raising) portion (minimum - maximum time) and cerebral arteriosclerosis was established by Jenkner (1970). He published in 1970 that "anacrotic part of REG (in seconds) as averaged from 100 phases in 178 normal persons and 246 arteriosclerotic subjects, all of which had been submitted to carotid arteriography" (Fig. 68 in Ref. 25). A publication certified REG from intracranial component (Perez, 2014). Nevertheless, previously, opposite opinions had been voiced, as well (Waltz and Ray, 1965, 1967, Perez-Borja, Meyer, 1964).

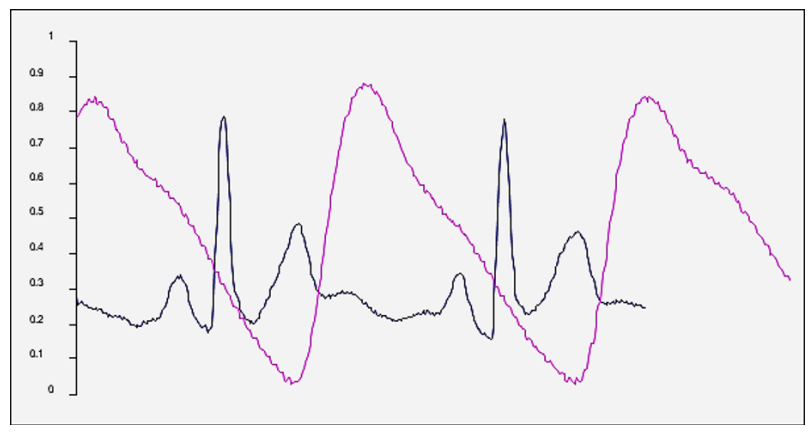

Figure 1. REG pulse wave (purple) and its relationship to electrocardiogram (blue). Pulse wave was inverted.

The advantages of REG are its non-invasive nature, the ability to monitor continuously, and low cost. A disadvantage is that REG is sensitive 
to movement artifact, much like EEG. There is an international organization for electrical bioimpedance (Anonymous 4) with regular conferences and journal (Anonymous 5). REG was listed as a noninvasive neuromonitoring method (Rubin et al., 2009).

REG data processing: Historically, REG analysis has calculated pulse amplitude changes in the waveform, recorded on paper in chart form, and analyzed visually. Contemporary REG analysis, accomplished by computerized data processing software, enables continuous CBF AR monitoring (REGx - Brady et al., 2010). Best illustration of how REG development is a multidisciplinary subject is the used data processing. In the 1970 s REG filtering was realized by using analogue filter and integrator. Additional data processing modules were also built based on analogue circuitry and a digital calculator was used to calculate absolute $\mathrm{CBF}$ by $\mathrm{H} 2$ clearance in animal studies. In addition, new REG devices were introduced (Peredi et al., 1981; Bodo et al., 1981; Peredi et al., 1987; Zoltai et al., 1987). From the late 1970s, software development has supported REG data processing (Jenkner, 1986; RheoSys: Montgomery, et al., 1989; Weinstein et al., 1978; Moskalenko, 1980; Sokolova at el, 1977; Sokolova and Yarullin, 1982; Jenkner, 1986). By this line 3 data acquisition systems were created and used to collect, display, and process REG and other physiological signals (Bodo et a, 1995, 1996; Heilig et al., 1998; Nagy et al., 2001; Baranyi et al., 2018). In addition to REG data processing, the Cerberus system (Bodo et al., 1995) provides a model for storing analog physiological signals in a computer-based medical record. Cerberus was prepared to be turned into an expert system, and was also tested (Kabakcioglu et al., 1994). Similarly, to EEG, REG data processing was also computerized (Traczewski et al., 2005; Meghdadi et al., 2019). Electrical impedance brain scanner was proposed in 1978 (Benabid et al); Maltron International becoming a manufacturer of Bioelectrical Impedance Analysers (BIA) and Electrical Impedance Tomography (EIT) imaging technology. There are many bioimpedance device/ BIA manufactures (Maltron, UFI, Medis, etc.), not only for REG but for lung function and body composition analysis. BIA analyzers are using a multifrequency measurement.

\section{2. $R E G$ related results}

REG - ICP - Cerebral blood volume correlation during $\mathrm{CO} 2$ inhalation in humans
The REG pulse amplitude relationship to cerebral blood volume was documented in humans with radio-iodinated human serum albumin (RIHSA) method during $\mathrm{CO} 2$ inhalation. This study revealed that REG transiently increased reflecting the intracranial blood volume increase and correlated with ICP increase, as well (Bodo et al., 1986; Bodo 1990).

\section{Cerberus system}

Stroke is unique among neurological diseases since it has a high incidence rate, severe burden of illness, high economic cost, and it may be preventable (Gorelick, 1994). Described here is a system for screening the cerebral- and vascular status of individuals to detect the initial stages of vascular disorders.

Cerberus, a computer based polygraphic system questions subjects about risk factors, stresses, neurologic symptoms of transient ischemic attack (TIA), and monitors impedance pulse waves of the head (REG) and extremities, EEG, and ECG. For technical details, see Bodo et al. (1995 and 1996).

\section{Cerberus measurement 1; Healthy group 1.}

In this study a Cerberus prototype was used, built in Budapest, Hungary, by Metracomp Ltd. The used program was GRAL (Nagy, et al., 2001).

Methods: A cross-sectional survey (546 subjects) was conducted in the early 1990 s, by means of the Cerberus system, which includes: 1. a questionnaire addressing the risk factors for stroke/cardiovascular disease; 2. amplifiers to record the pulse waves of cerebral (REG) and peripheral arteries, EKG, and EEG. Additionally, subjects were measured for carotid stenosis by Doppler ultrasound and 12-lead ECG; they were also screened for blood cholesterol, glucose, and triglyceride levels. REG was considered arteriosclerotic if its anacrotic (rising) portion was above the $180 \mathrm{~ms}$ threshold, modified after Jenkner (1970). Additionally, anxiety, depression, dementia, neurosis was evaluated (Sipos et al., 2008).

Findings: Prevalence of the following stroke risk factors was identified: overweight, $63.25 \%$; sclerotic brain arteries by REG, 54.29\%; heart disease, 37.92\%; pathologic carotid flow, 34.24\%; smoking, 30.55\%; high blood cholesterol, $28.70 \%$; hypertension, $27.83 \%$; high triglyceride, $24.35 \%$; abnormality of electrocardiogram, 20\%; high glucose level, $15.95 \%$; symptoms of transient ischemic attack, 16.07\%; alcohol abuse, 6.74\%; and diabetes, 4.53\% (Bodo et al., 1992, 1998, 2008). 


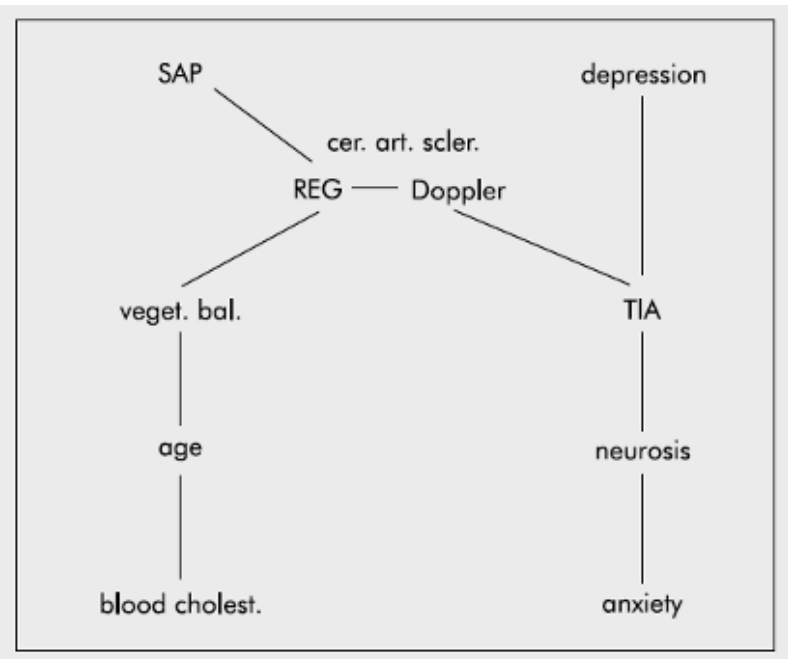

Figure 2. Significant correlations among measured variables. Cerebrovascular alteration (REG-Doppler-TIA) was in a bridge position between measured somatic (left) and psychological (right) variables $(n=546, p<0.05)$. SAP: systemic arterial pressure; cer. art. scler: cerebral arteriosclerosis; REG: rheoencephalogram; Doppler: carotid flow systolic velocity measured by Doppler ultrasound; veget. bal: vegetative balance by Kerdo-Sipos; blood cholest: blood level of total cholesterol; TIA: symptoms of transient ischemic attack entered Cerberus inquiry (Sipos et al, 2008). Conclusion: The study demonstrates a possible model for primary cardiovascular disease/stroke prevention. The simple, noninvasive test uses the bioimpedance method of measurement. This method offers a standardizable, cost-effective, practical technique for mass screenings by identifying the population at high risk for cardiovascular disturbances, especially cerebrovascular disease. In this model, REG can detect cerebrovascular arteriosclerosis in the susceptibility/presymptomatic phase, earlier than the Doppler ultrasound technique.

\section{Cerberus measurement 2; Psychiatric}

\section{population and healthy group 2}

In our next study we used an upgraded Cerberus system, built in Budapest, Hungary, by Quintlab Ltd. The program was a newly developed software (Heilig et, et al., 1998 and Quintlab Ltd.).

Methods: Test subjects were 48 alcoholic patients in Hungary; the control group consisted of 12 drug-addicted and depressed patients in Hungary and 13 healthy male subjects in the United States. Additional subgroups were formed according to smoking habits and average daily alcohol dose. REG was measured by a computer-based system, Cerberus; REG anacrotic time above $180 \mathrm{~ms}$ was considered pathological (Szalay et al., 2006).

Findings: ANOVA showed that daily alcohol consumption and smoking were significantly greater for alcohol abusers than for drug-addicted and depressed patients. Twelve alcoholics showed a pathological REG anacrotic time. Longer REG anacrotic time was correlated with higher daily alcohol consumption. In the alcoholic group, the steeper regression line of REG slope reflected the pathological impact of alcohol abuse. The healthy control sample showed a nearly identical slope for both REG and age. Correlation of increased REG anacrotic time and daily alcohol consumption supports the hypothesis that REG detects accelerated cerebrovascular aging (arteriosclerosis) in alcoholic subjects.

Conclusion: Obtained data support the hypothesis that a correlation exists between anxiety, excessive alcohol consumption and cerebrovascular disorders (Sipos and Bodo, 2019).

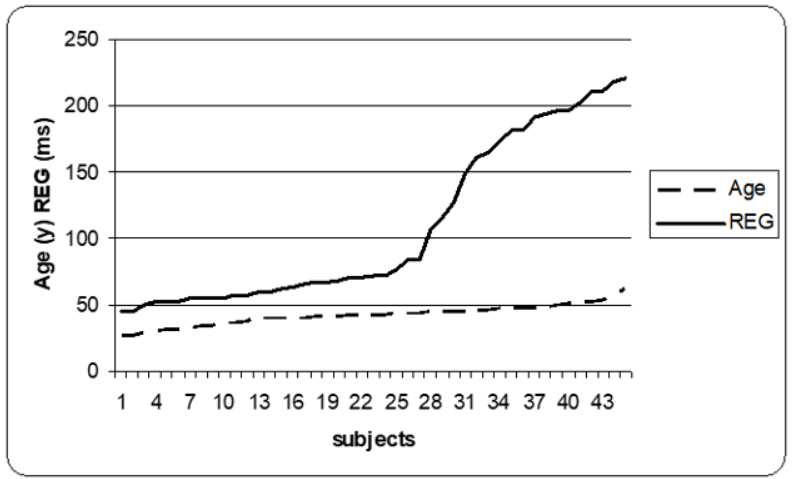

Figure 3. Sorted age and REG anacrotic time in alcoholic group. Sorted age and REG anacrotic time in alcoholic group. The steeper REG anacrotic time slope reflected the pathological impact of alcohol abuse. After being sorted independently for REG anacrotic time and for age, these variables showed the following regression values: age, $y=0.5697 x+29.341 R 2=0.9398$ (linear); $R E G$ anacrotic time, $y=4.3882 x+7.4492 \quad R 2=0.8682$ (linear) and $y=36.685 e$ $0.0404 \times$ R2=0.9279 (exponential).

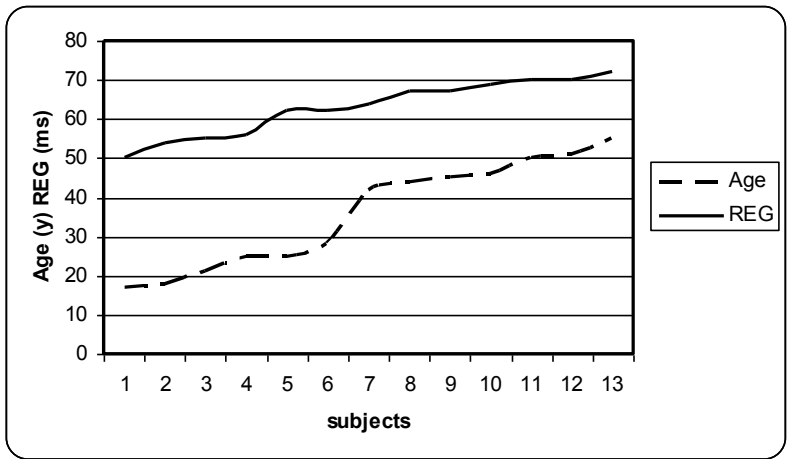

Figure 4. Sorted age and REG anacrotic time in healthy group. Sorted age and REG anacrotic time in healthy group. Physiological cerebrovascular aging. REG anacrotic time showed an identical slope with age. Age and REG regression values (calculated as one group, $n=13$ ) are as follow: Age: $y=3.4505 x+11.769, \quad R 2=0.9509$, and REG anacrotic time: $1.7912 x+50.385, R 2=0.9527$ (both linear). 


\section{Cerberus measurement 3; Mobile phone testing}

Cerberus system was used to measure brain effect of mobile phone use (Thuroczy, et al., 1999). A slight decrease in the REG amplitude during the exposure was observed.

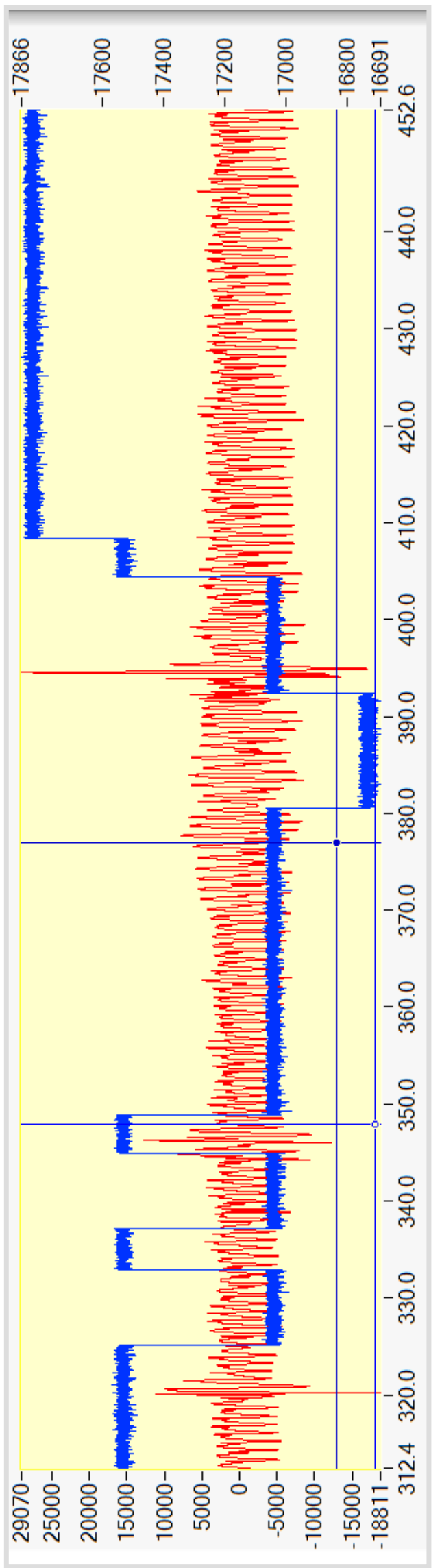

Cerberus measurement 5; Demo and measurement*

Table 1: Events and Academic Institutions in Europe

\begin{tabular}{|l|l|c|}
\hline \multicolumn{1}{|c|}{ Event } & \multicolumn{1}{|c|}{ Location } & Year \\
\hline International Fair & $\begin{array}{l}\text { Budapest, } \\
\text { Hungary }\end{array}$ & $\begin{array}{c}1991, \\
1992\end{array}$ \\
\hline $\begin{array}{l}\text { Salon International de } \\
\text { L'invention de Paris } \\
\text { (Concours Lepine) }\end{array}$ & $\begin{array}{l}\text { Paris, } \\
\text { France }\end{array}$ & 1993 \\
\hline $\begin{array}{l}\text { International Technical } \\
\text { Expo }\end{array}$ & $\begin{array}{l}\text { Hannover, } \\
\text { Germany }\end{array}$ & 1994 \\
\hline $\begin{array}{l}\text { Semmelweis Medical } \\
\text { School, Geriatric } \\
\text { Research Center }\end{array}$ & Budapest, & 1994 \\
\hline $\begin{array}{l}\text { University of Physical } \\
\text { Education }\end{array}$ & $\begin{array}{l}\text { Budapest, } \\
\text { Hungary }\end{array}$ & 1996 \\
\hline $\begin{array}{l}\text { Frédéric Joliot-Curie } \\
\text { National Research } \\
\text { Institute for } \\
\text { Radiobiology and } \\
\text { Radio Hygiene }\end{array}$ & Budapest, & 1997 \\
\hline
\end{tabular}

${ }^{*}$ Cerberus was the only awardee by the French Minister of Scientific Research

Table 2: Events and Academic Institutions in USA

\begin{tabular}{|l|l|l|}
\hline \multicolumn{1}{|c|}{ Event } & \multicolumn{1}{|c|}{ Location } & Year \\
\hline $\begin{array}{l}\text { International Expo of } \\
\text { Invention }\end{array}$ & $\begin{array}{l}\text { Pittsburgh, } \\
\text { Pennsylvania }\end{array}$ & 1993 \\
\hline $\begin{array}{l}\text { University of Miami } \\
\text { School of Medicine, } \\
\text { Department of } \\
\text { Neurology }\end{array}$ & $\begin{array}{l}\text { Miami, } \\
\text { Florida }\end{array}$ & 1994 \\
\hline $\begin{array}{l}\text { Massachusetts Institute } \\
\text { of Technology, Clinical } \\
\text { Research Center }\end{array}$ & $\begin{array}{l}\text { Boston, } \\
\text { Massachusett } \\
\text { s }\end{array}$ & 1995 \\
\hline $\begin{array}{l}\text { Life Resuscitation } \\
\text { Technologies, Inc. }\end{array}$ & $\begin{array}{l}\text { Chicago, } \\
\text { Illinois }\end{array}$ & 1996 \\
\hline $\begin{array}{l}\text { University of South } \\
\text { Florida, Department of } \\
\text { Neurology and Public } \\
\text { Health }\end{array}$ & $\begin{array}{l}\text { Tampa, } \\
\text { Florida }\end{array}$ & 1996 \\
\hline $\begin{array}{l}\text { Health Department } \\
\text { Bealtimore, }\end{array}$ & 1998 \\
\hline
\end{tabular}

*NB: The above list shows Cerberus system demos/use. After 2000, only the Cerberus amplifier was used in USA. 


\section{Cerberus measurement 4; Healthy group 3}

The US FDA concluded that Cerberus is a "nonsignificant risk device". An electromagnetic safety test has proven its applicability (MET Laboratories, Inc., Baltimore MD, 2009).

The cited study compares cerebrovascular reactivity monitored by $\mathrm{REG}$, a noninvasive continuous monitoring modality, to cerebrovascular reactivity measured by currently used neuromonitoring: transcranial Doppler (TCD), near infrared spectroscopy (NIRS), and laser Doppler flowmetry (LDF). Fourteen healthy volunteer subjects were examined. Tests used for comparison of cerebrovascular reactivity were breath-holding, hyperventilation, $\mathrm{CO} 2$ inhalation, the Valsalva maneuver, and the Trendelenburg and reverse Trendelenburg positions. Data for all modalities were recorded by computers and processed offline. All measured modalities reflected cerebrovascular reactivity with variabilities. Breath-holding, $\mathrm{CO} 2$ inhalation, and the Valsalva maneuver caused $\mathrm{CO} 2$ increase, resulting in brain vasodilatation; hyperventilation caused $\mathrm{CO}_{2}$ decrease and brain vasoconstriction. The Trendelenburg and reverse Trendelenburg positions caused extracranial blood volume changes, which masked intracranial cerebrovascular reactivity. The hyperventilation test was ineffective for measuring cerebrovascular reactivity with REG due to respiratory artifacts. Some discrepancies among the various tested modalities were observed. Further validation studies are under preparation to test the applicability of REG for noninvasive continuous brain monitoring, including enhanced computational methods, animal studies and clinical monitoring studies of humans (Bodo et al., 2017).

\section{In vitro bioimpedance validations}

Based on preliminary results, REG shows promise as a practical, noninvasive, and continuous monitoring modality of brain injuries. However, REG literature reflects uncertainty about whether the signal reflects flow or volume. Presented here are results of in vitro studies manipulating flow/ volume to model clinical conditions (such as brain ischemia and vasospasm) while recording the electrical impedance signal. A loop was created using tubing filled with $0.9 \% \mathrm{NaCl}$. This loop was comprised of a Doppler in-line flow probe connected to an ultrasound flow meter, a peristaltic pump, a pressure transducer, and homemade electrical impedance measuring cell, incorporating a balloon catheter. Bipolar impedance amplifiers were used to measure the impedance pulse waves. Data were stored on a PC and processed off-line. This in vitro study confirmed that 1) Doubling flow rate influenced the pulse amplitude and mean flow of the Doppler signal; 2) Doubling flow rate had no influence on the amplitudes of the pressure or electrical impedance signals; 3) An increase in amplitude was observed in the pressure and electrical impedance signals when the first derivative was taken.

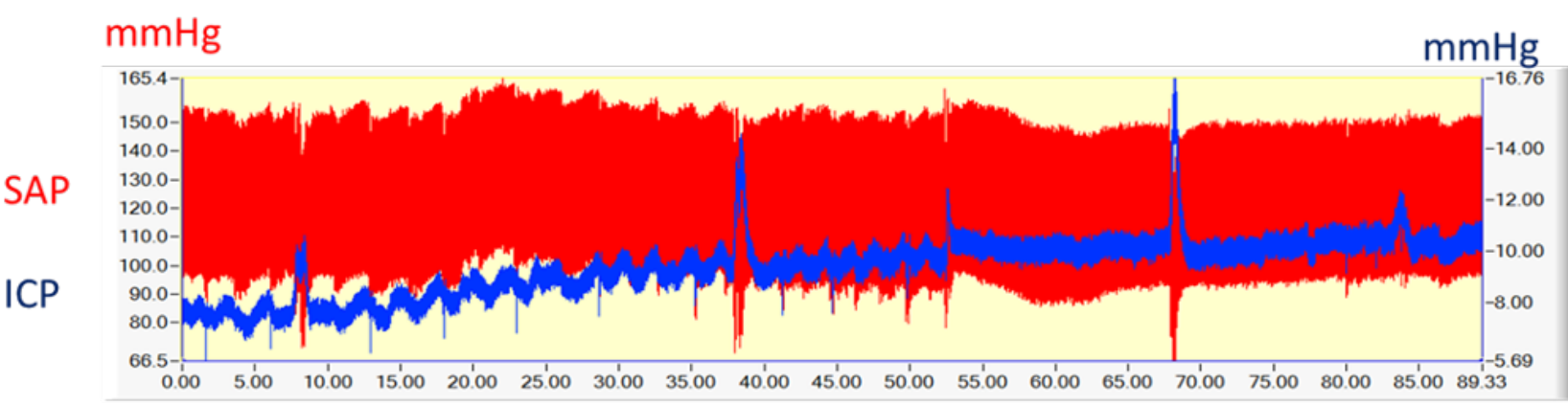

$\min$

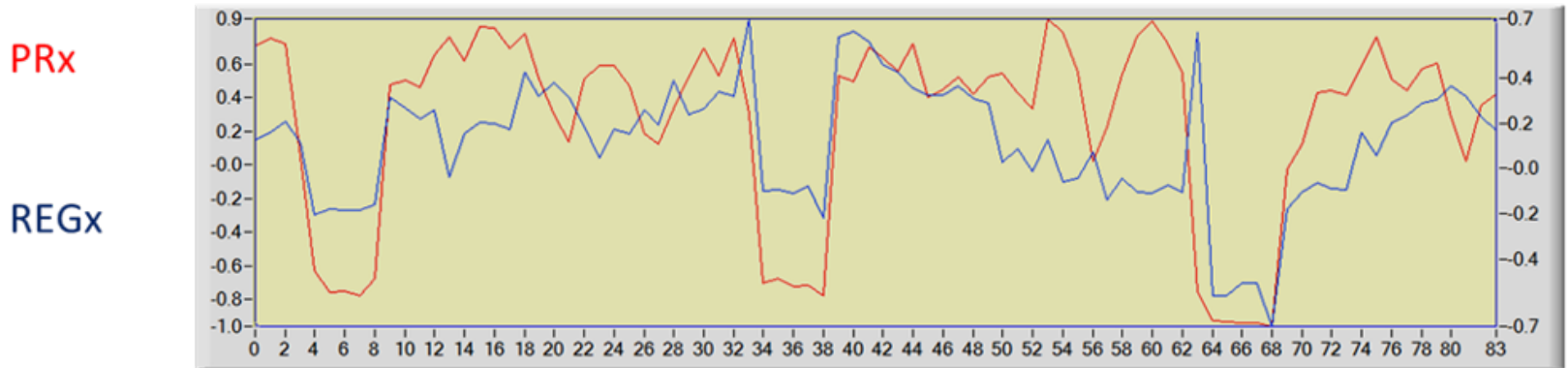

$\min$

Figure 6. PRx - REGx comparison during vinpocetine injections in rat.PRx - REGx comparison during vinpocetine injections in rat. Upper panel: SAP (red) and ICP (blue) traces. Blue ICP peaks indicate time of vinpocetine injections (n=3). 
4) Balloon inflation decreased electrical impedance and Doppler flow pulse amplitudes; 5) With balloon inflation, Doppler and electrical impedance signals showed an identical relationship to decreased flow $(\mathrm{R} 2=0.966)$ (Bodo, 2010).

\section{In vivo animal studies}

Microwave exposure on rats: REG pulse wave amplitude increased after $10 \mathrm{~min}, 10 \mathrm{~mW} \mathrm{~cm}^{-2}$, $2450 \mathrm{MHz}$ microwave exposure (Thuroczy et al., 1992).

CBF manipulations on rats (Figure 6): Several groups were used for measuring REG pulse amplitude change during electrical stimulation, carotid clamping, hemorrhage, $\mathrm{CO} 2$ inhalation, vinpocetine injection. REG was compared to carotid flow, laser Doppler flow, ICP, SAP, and spreading depolarization (Bodo et al., 2003, 2004, 2005, 2010, 2015, 2016).

\section{CBF manipulations on pigs}

Several groups were used for establishing REG pulse waveform change during aortic compression, progressive hypotension, Doxil injection, hemorrhage, CO2 inhalation, positive end expiratory pressure (PEEP). REG was compared to carotid flow $(\mathrm{CF})$, laser Doppler flow, ICP, SAP, absolute CBF, and pulse oximeter signal. Additionally, REGx was compared to PRx (Brady et al., 2010; Popovic et al., 2013; Bodo et al., 2015, 2018). During aorta compression, systemic arterial pressure increased $(\mathrm{p}=0.008)$, and REG amplitude decreased. Doxil injection caused a transient brain vasospasm, prior to systemic cardiorespiratory changes, which may explain symptoms in patients during Doxil infusion (Bodo et al., 2005). When CBF AR was present, it was detected by both REG and carotid flow. Following hemorrhage, CBF AR was lost; $\mathrm{CF}$ and REG passively followed SAP (Bodo et al., 2007). PEEP after hemorrhage caused loss of CBF AR, may occur during hypotensive resuscitation. REG and carotid flow showed strong linear relationship (Bodo, 2010).

\section{CBF manipulations on rabbits}

Rabbits were used for establishing REG correlations during hemorrhage, $\mathrm{CO} 2$ inhalation, acetazolamide injection, hyperventilation, PEEP, and SAP changes. REG was compared to laser Doppler flow, ICP, SAP, absolute CBF, brain tissue temperature, pulse oximeter signal, and exhaled $\mathrm{CO} 2$ level. Visual inspection suggests correlation among $\mathrm{CBF}$, ICP, brain tissue $\mathrm{O} 2$, temperature, LDF and REG during challenges. In total, 47 correlations (positive and negative together) were established. CBF AR was active in 6 animals and passive in 7 animals. Demonstrated $\mathrm{CO} 2$ decreasing effect of acetazolamide has a potential clinical application in neurosurgical care that demands strict avoidance of hypercapnia and hypocapnia (Christy et al., 2014). We present correlations among various modalities. Though statistical analysis has not been completed, continuous non-invasive measurement of $\mathrm{CBF}$ appears to correlate with invasive measurements (Bodo et al., 2014).
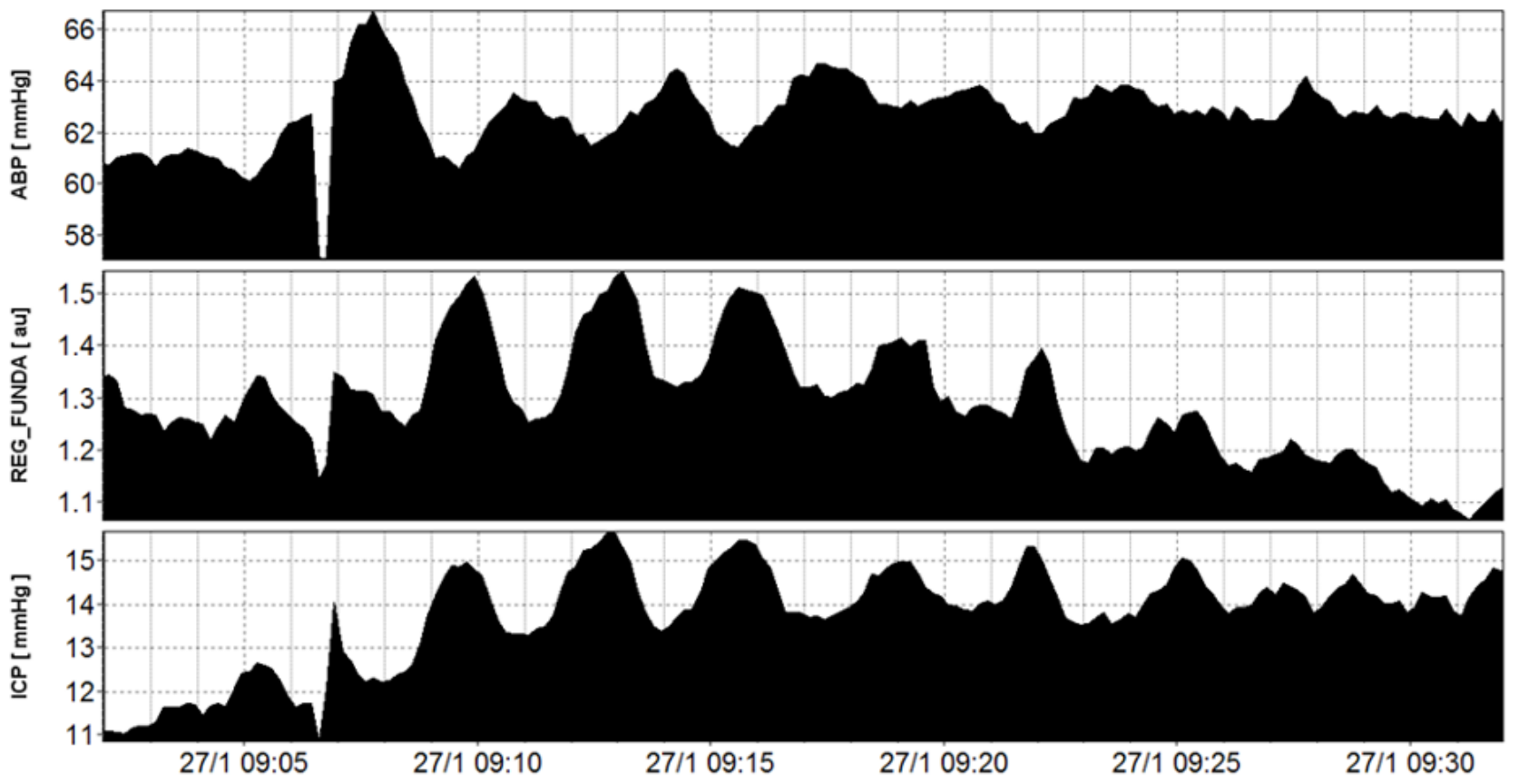

Figure 7. The physiological basis of REGx calculation: identical changes of ICP and REG. Slow waves of arterial blood pressure (ABP), ICP are compared with a trend of pulse-frequency amplitude changes in REG (FundA). Slow waves of ICP 


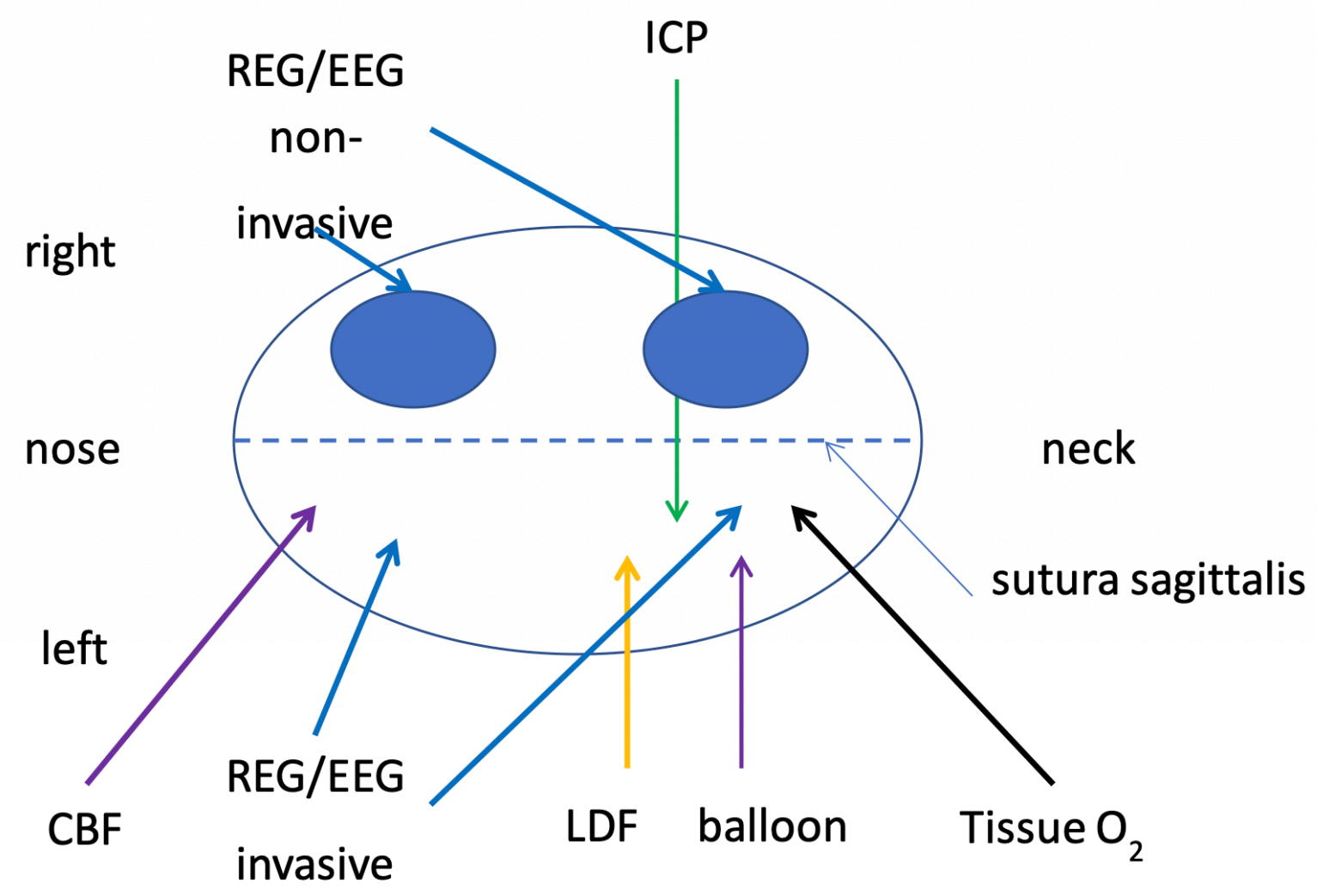

Figure 8. Electrode and sensor location.

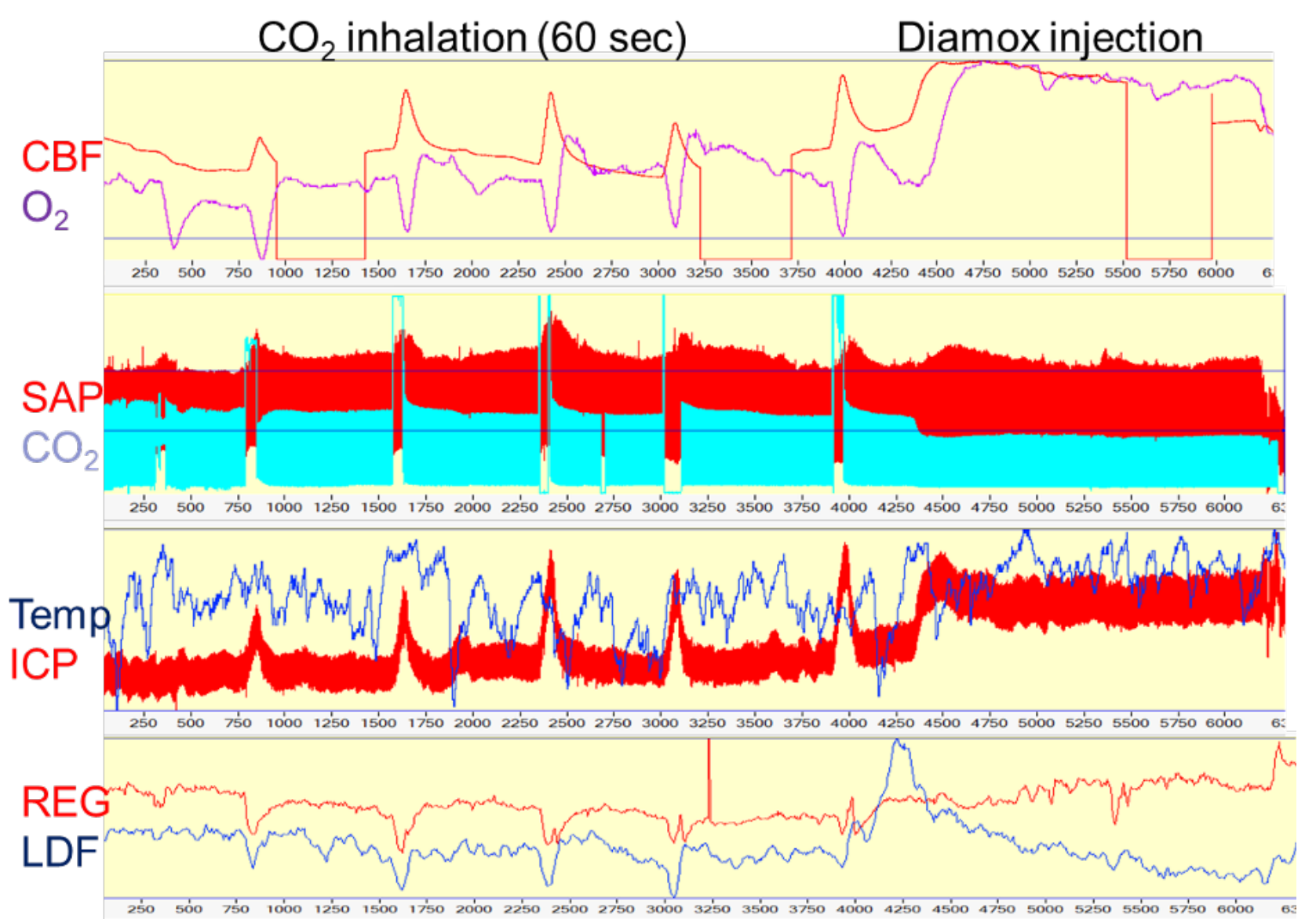

Figure 9. Invasive CBF Modalities (rabbit): Demonstration of $\mathrm{CBF}$ heterogeneity during $\mathrm{CO}_{2}$ inhalations (n=5 and Diamox injection. Rabbit Aug 21. 
Discrepancy of CBF measuring modalities can be explained by brain tissue heterogeneity of $\mathrm{CBF}$ and different locations of sensors. Additionally, REGx documented the overdose of anesthesia; PRx values showed passive or absence of CBF AR (Felbaum et al., 2015, Felbaum et al., 2015).

\section{CBF manipulations on monkeys}

We developed a software module (DataLyser), which was able to determine the lower limit of CBF AR in monkey experiments (Bodo et al., 2010). The importance of this statement is that REG electrodes were on the skin of skull. Meaning, that REGx calculation is operational in noninvasive manner (Popovic et al., 2013).

\section{Neurocritical Care patients}

ICP is more than a number. This slogan may mean that apart from its mean value, ICP contains many transients and waves, which are useful for describing intracranial pathology (Czosnyka and Czosnyka, 2020). Fortunately, such information is present in REG waveform. REG and lower arm bioimpedance were measured to calculate REGx. REGx reflected 1) status of intracranial compliance; 2) healthy or sclerotic brain arterioles; and 3) level of ICP - indirectly, by identical pulse wave change as ICP pulse wave
(McHenry, 1965, Jenkner, Canizzarro et al., 2019; Czosnyka and Czosnyka, 2020).

\section{Discussion}

\section{Cardiovascular disease}

Cardiovascular diseases (CVDs) are a group of disorders of the heart and blood vessels of brain; CVDs are the number one cause of death globally: more people die annually from CVDs than from any other cause. An estimated 17.9 million people died from CVDs in 2016, representing $31 \%$ of all global deaths. Of these deaths, $85 \%$ are due to heart attack and stroke. Over three quarters of CVD deaths take place in low- and middle-income countries. Heart attacks and strokes are usually acute events and are mainly caused by a blockage that prevents blood from flowing to the heart or brain. The most common reason for this is a buildup of fatty deposits on the inner walls of the blood vessels that supply the heart or brain. Strokes can also be caused by bleeding from a blood vessel in the brain or from blood clots. The cause of heart attacks and strokes are usually the presence of a combination of risk factors, such as tobacco use, unhealthy diet and obesity, physical inactivity and harmful use of alcohol, hypertension, diabetes, and hyperlipidemia [WHO]. The etiology of CVD/ stroke is arteriosclerosis/atherosclerosis.

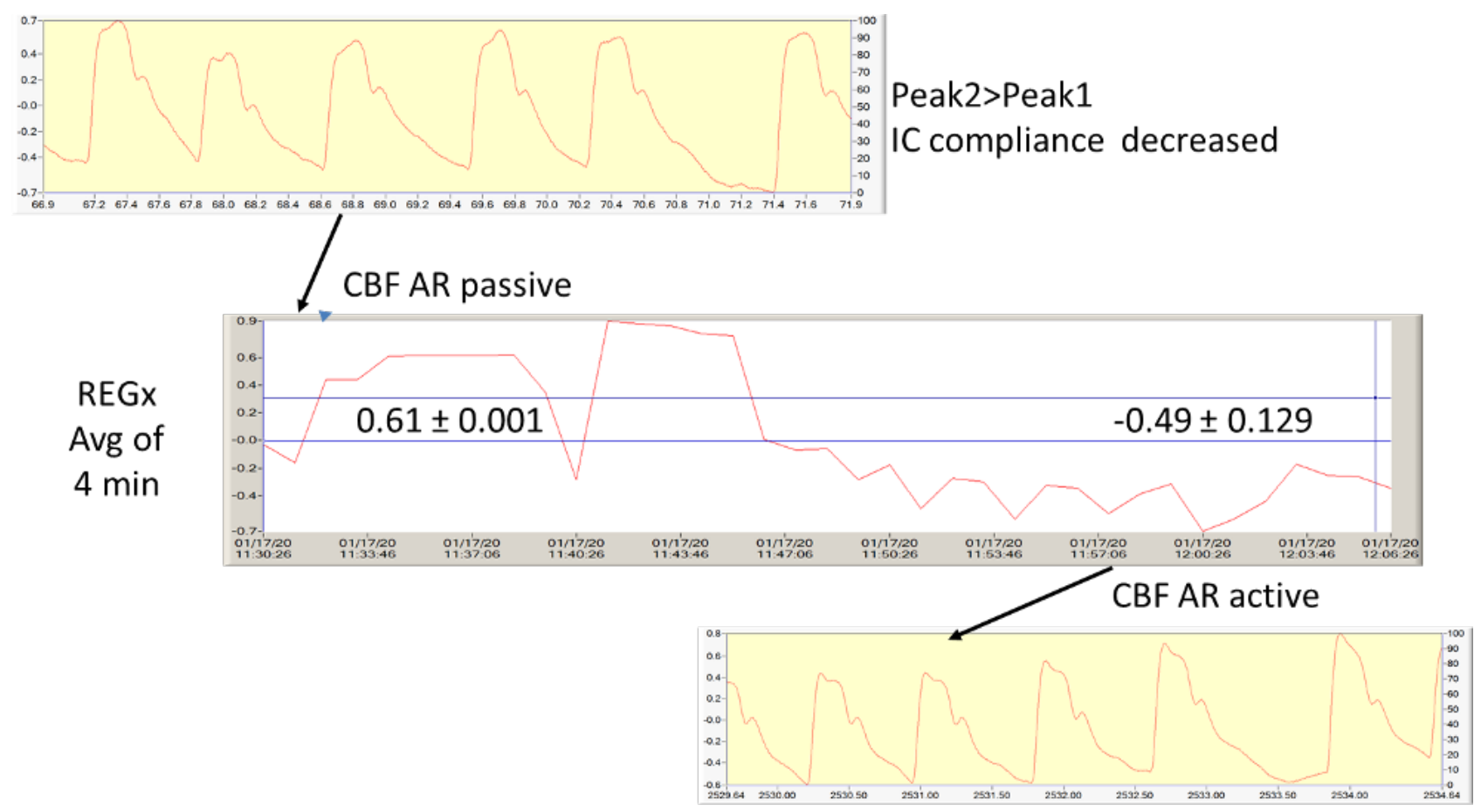

Jan 17, 2020

Figure 10. REG waveform comparison. Upper trace: REG waveform at the beginning of recording. Note: second peak (P2) is higher than first (P1) - reflecting elevated ICP and decreased IC compliance. Middle trace: REGx during recording.

Time window for REGx: 36 min. At beginning REGx is closer to 1; during second half it is decreasing, trending to -1. Note: second peak is lower than first - reflecting decreased ICP and normal IC compliance. Mean REGx was 0.61 at start and -0.49 at end (average of $4 \mathrm{~min}$ ). NB: +1: passive; -1: active CBF AR. No sing of arteriolar arteriosclerosis; REG anacrotic/ rising time is $102.56 \pm$ msec; $n=10$. 


\section{Stroke}

The etiology of stroke is multifactorial. Stroke is the leading cause of death worldwide and a leading cause of disability (Anonymous 7). There is a current lack of large-scale adequate screening programs designed to date to detect people with hypertension before inevitable complications of heart disease, strokes, kidney disease, or visual problems occur (Anonymous 8). A radical decrease in stroke death (80\%, Anonymous 9; de Freitas, Bogousslavsky, 2001) can be obtained by the introduction of primary prevention, i.e., screening the general population from age 40 to find high risk population. Cerberus system was created for this purpose. REG measurement is more sensitive at detecting brain arteriosclerotic status than carotid Doppler measurement (Bodo et al., 1998; 2008). This suggests that it may be a significantly improved means for the differential diagnosis of neurological disease and the screening of subjects for arteriosclerosis, TIA, and stroke prevention to be offered at the lowest level of medical service. COVID-19 infection itself has also been described as a risk factor for stroke (Markus and Brainin, 2020). History of stroke increases the risk of death caused by COVID-19, by a factor of 3. COVID-19 currently seems to be one of the main complications of stroke and CVD (Trejo, 2020).

\section{Pathophysiology}

Arteriosclerosis has been described as a progression that occurs in two phases. The first phase proceeds at a slow rate, related to accumulation of foam cells, creation of fatty streak, transformation of lipoid accumulation to crystalline cholesterol, and accumulation of cellular components such as smooth muscle cells and fibroblasts. During this phase, changes occur in the elasticity of the artery wall, but not in the lumen, and there is generally a form of compensatory remodeling of the external elastic lumina and muscular wall that allows preservation of the luminal to conduct blood flow. The second phase of arteriosclerosis occurs at "a rapid rate" (related to plaque fissuring and/or hemorrhaging leading to platelet rich thrombus accumulation (Mancini, 1995). During this phase, there are changes in the lumen and in the artery wall, as well (Yatsu and Fischer, 1989). These two phases may correspond to the known stages of prevention levels of chronic disease, called "upstream" (prevention level 1-2) and “downstream” (prevention level 3-4) (Mausner and Kramer, 1985).

\section{Cerebral Blood Flow Autoregulation}

In the brain, $\mathrm{CBF}$, metabolism, and function are strongly interrelated. Although the mechanism of this complex system is not well known, there is satisfactory scientific and clinical evidence supporting the use CBF AR (cerebrovascular reactivity) for diagnostic monitoring purposes. CBF AR is defined as the phenomenon that makes blood flow constant despite variations in SAP (Strandgaard and Paulson, 1984). CBF reacts to changes in perfusion pressure (SAP-ICP), due to adaptation of the vasculature of the brain. Cerebral vascular resistance varies in response to variations of SAP. Blood vessels in the brain constrict or dilate in response to changes in SAP between about 50-150 mmHg SAP. Below and above this limit or in pathological cases, CBF passively follows SAP. Without autoregulation, CBF would increase or decrease, with possible cerebral ischemia or edema, whenever the perfusion pressure increases or decreases. Thus, CBF AR in the cerebral circulation may be defined more pragmatically as the mechanism that protects the brain against the dangers of hypoxia, at low perfusion pressures, and against the risks of brain edema, at high arterial pressures. Based on this definition, $\mathrm{CBF}$ AR may be thought of as a homeostatic mechanism that is superimposed over and above the baroreceptor reflexes. The anatomical background of CBF AR is the arteriole. Arterioles represent the last small branches of the arterial system, and they act as control valves through which blood is released into the capillaries. The arteriole has a strong muscular wall, capable of closing the arteriole completely or of allowing it to be dilated severalfold, thus having the capability of vastly altering blood flow to the capillaries in response to the needs of tissue (Guyton, 1991, Kontos et al., 1978).

\section{Neuromonitoring}

The goal of neuromonitoring is to prevent secondary brain damage. CBF AR is pivotal to the maintenance of appropriate $\mathrm{CBF}$. Impaired $\mathrm{AR}$ may lead to secondary damage from neuroexcitotoxicity and is an independent predictor of poor outcome following traumatic brain injury (TBI). The goal of 'real-time' continuous CBF AR monitoring is to be able to optimize treatment strategies according to evolving physiologic parameters. 
Traumatic brain injury (TBI) is a major cause of death and disability among soldiers and young individuals. A worse outcome is associated with ongoing secondary insults. Current Brain Trauma Foundation guidelines (Carney et al., 2017) regarding the management of patients after TBI include the reduction of ICP below $20 \mathrm{mmHg}$ and maintenance of cerebral perfusion pressure (CPP) between 50 and $70 \mathrm{mmHg}$. Bedside assessment of CBF AR may help to optimize individual CPPguided treatment. A new method of autoregulationguided treatment is based on continuous evaluation of cerebrovascular reactivity (PRx).

CBF AR (cerebrovascular reactivity) is tested, whether it is passive or active. Such tests are breath holding, hyperventilation, $\mathrm{CO} 2$ inhalation, and acetazolamide/Diamox injection (Ringelstein et al., 1992). Mild brain trauma in the setting of polytrauma may cause cerebrovascular dysregulation. Hemodynamic manipulation in polytrauma, e.g., hypotension, may be damaging to the brain, because of loss of AR.

A continuous monitoring of CBF AR status (active/passive) is possible with a program, called $\mathrm{ICM}+$ (Anonymous 6). The fundamental relationships between $\mathrm{SAP}$, vessel tone, cerebral blood volume, and ICP form the basis for the pressure reactivity index (PRx) (Czosnyka, et al., 1997). PRx is analogous to other time domain AR indices and is calculated as the continuous correlation between 30 consecutive time-averaged $(10$ s) SAP and ICP values. A positive index (positive correlation) implies impaired/passive cerebral autoregulation, while a negative index (inverse correlation) implies intact/active AR.

Previous studies documented that 1) REG reflects cerebrovascular reactivity/CBF AR; 2) REGx and $\mathrm{PRx}$ are correlated to detect the lower limit of $\mathrm{CBF} A \mathrm{AR}$; the area under the receiver-operator curve for the REGx is 0.86 (Brady et al., 2010); and 3) REGx can be measured with skin/scalp electrodes [Bodo et al., 2010].

Neurocritical care society (NCS) guidelines and consensus statements are detailed elsewhere (NCS). Ideally, neuromonitoring would be noninvasive and continuous. Bioimpedance/REG can accomplish this task.

\section{Space research and REG}

It has been documented that space flight damages astronauts' CBF AR. Symptoms of increasing intracranial volume/pressure (ICP) and impaired CBF AR have been linked to space flightassociated neuro-ocular syndrome, orthostatic intolerance, headache, and impaired neurocognitive performance (Yegorov, 1979; Blaber et al., 2011; Law et al., 2014; Hughson et al., 2016; Iwasaki et al., 2007; Zuj et al., 2012; Taylor et al., 2013; Arbeille et al., 2016; McDonald, 2009; Klein et al., 2019).

Although NASA has sought development of a real time noninvasive monitoring method of ICP for use on the International Space Station (ISS), until recently no noninvasive, continuous brain monitoring device has been available to measure CBF AR on ISS. Because ICP measurements are invasive, they are not performed in real time on astronauts, while on the ISS, but only after they return from the space mission. Transcranial Doppler is then used to determine CBF in the middle cerebral artery, but CBF AR, a function of smaller vessels arterioles, is not measured. After studies by the US Army proved that a real-time measuring technique, REG, reflects both CBF AR and ICP, the US Department of Defense supported development of a noninvasive, continuous brain monitor, using REG technology (Meghdadi et al., 2019). Unit dimensions are: 85 x 58 x $16 \mathrm{~mm}$; mass: $102.06 \mathrm{~g}$ [ABM]. This operator-independent device calculates REGx in real time, utilizing regular ECG electrodes, dry electrodes, or reusable conductive fabric, placed on the forehead and lower arm.

A recent publication details impacts of spaceflight and spaceflight analogs on CBF AR (Kermorgant et al., 2020).

Additionally, such monitors can be used in military aviation. Modern jet planes fly under computer control and can do maneuvers that a pilot cannot tolerate, because of CBF decrease. Unfortunately, this physiological variable is not stored in black box. However, REG (or other noninvasive) sensors can be placed in helmet and offer earliest signal of losing consciousness and urgent need to switch to autopilot mode.

\section{Conclusions}

Results indicate that REG accurately reflects cerebrovascular reactivity (CBF AR), similarly to ICP, carotid flow, etc. Bioimpedance/REG pulse amplitude change reflects blood and cerebrospinal volume change, rather than absolute CBF (Bodo et al., 1986; Bodo 1990, 2010). Clinical importance of these findings is that REG can be measured noninvasively, conveniently, and continuously in humans. It has been demonstrated that REG is able to identify cerebrovascular arteriosclerosis caused by decreased (Windkessel effect) brain vasospasm during Doxil injection, passive CBF AR during PEEP and anesthesia overdose. Therefore, measurement of $\mathrm{CBF} A \mathrm{R} / \mathrm{REG}$ has potential for 
use as a life sign monitoring modality in civilian, military medicine, and in military aviation and space research, as well. Specifically, since the REG device was miniaturized and computerized (Meghdadi et al., 2019), NB: CO2 level on ISS $(4.0 \mathrm{mmHg})$, requires validating a practical test of $30 \mathrm{~s}$ breath holding. Previous study (Bodo et al., 2017) demonstrated usefulness of this test, but only on Earth $(0.3 \mathrm{mmHg})$. Future studies need to clarify REGx normative in healthy persons (does not exist) and threshold for alarm in vital sign monitor. The initial alarm can be raised, when there is a loss of CBF AR by REGx, while the second can be the cessation of EEG for $2 \mathrm{~s}$, and respiration (Bodo et al., 2013).

Either in spaceflight or in ground-based model of microgravity, most of short-term studies show a preserved or even an improved CBF AR. Nevertheless, long-term studies depict an impairment in CBF AR. One of the main reasons of the discrepancy may depend on baseline orthostatic tolerance. Indeed, subjects who are orthostatically tolerant have a preserved or even an enhanced CBF AR. In contrast, orthostatically intolerant subjects would present an impaired CBF AR (Kermorgant et al., 2020). In present an adequate device is already available to measure CBF AR on ISS.

\section{Acknowledgements}

Recognition goes to all coauthors and technical support, listed in the publications below; Dr. Lajos Baranyi, Matthew Dennis, Frederick Pearce for DataLyser and REGx script development: Victoria Rahaman for editorial help.

\section{References}

ABM. Advanced Brain Monitoring Inc. Brain Monitor 1 ( B M - 1) Us e r M a u l. ht ps : / / www.advancedbrainmonitoring.com/ Accessed $7 / 8 / 2020$

Anonymous 1. 21CFR882.1825. Rheoencephalograph. (a) Identification. Code of Federal Regulations. Sec. 882.1825. Washington, D.C. U.S. Government Printing Office, Vol. 8. Title 21, Parts 800 to 1299; revised April $1,1997$.

Anonymous 2. https://pubmed.ncbi.nlm.nih.gov/? term $=\% 09$ Rheoencephalography Accessed 7/8/2020.

Anonymous 3. Wheatstone bridge: https:// www.electronicshub.org/wheatstone-bridge/
Anonymous 4. International Society for Electrical Bioimpedance http://www.isebi.org/ Accessed 7/8/2020

Anonymous 5. J. Electrical Bioimpedance. https:// content.sciendo.com/view/journals/joeb/joeboverview.xml Accessed 7/8/2020

Anonymous 6. ICM+ program: Software for Brain Monitoring in Neurological Intensive Care: http:// www.neurosurg.cam.ac.uk/pages/ICM/about.php

Anonymous 7. https://www.stroke.org/en/about-theamerican-stroke-association (Accessed 7/8/2020).

Anonymous 8. The National Health Education Committee. The Killers and the Cripplers. Facts on major Diseases in the United States Today, D. McKay Co.: New York, 1976.

Anonymous 9. https://www.ninds.nih.gov/Disorders/ Patient-Caregiver-Education/Preventing-Stroke Accessed 7/8/2020

Arbeille P, Provost R, Zuj K. Carotid and Femoral Artery Intima-Media Thickness During 6 Months of Spaceflight. Aerosp Med Hum Perform. 2016 May;87(5):449-53. doi: 10.3357/AMHP.4493.2016.

Baranyi L, Dennie M, Pearce, J. DataLyser program for data collection, visualization, and processing of analog physiological signals. Walter Reed Army Institution of Research, Silver Spring, MD; DDL OMNI Engineering, LLC, McLean, VA. 2018.

Benabid AL, Balme L, Persat JC, et al. Electrical impedance brain scanner: principles and preliminary results of simulation. TIT J Life Sci. 8(1-2):59-68. 1978.

Blaber AP, Goswami N, Bondar RL, Kassam MS. Impairment of cerebral blood flow regulation in astronauts with orthostatic intolerance after flight. Stroke. 42(7):1844-50. doi: $10.1161 /$ STROKEAHA.110.610576 2011.

Bodo et al. Rheoencephalographic changes during increased intracranial pressure. In: Krieglstein J (ed): Pharmacology of Cerebral Ischemia. Elsevier, Amsterdam, pp. 265-269, 1986.

Bodo $\mathrm{M}$, et al. A complex cerebrovascular screening system (Cerberus). Medical Progress through Technology 21:53-66. 1995. 
Bodo M, et al. Prevalence of stroke/cardiovascular risk factors in rural Hungary - a cross-sectional descriptive study. Ideggyogy Sz, 61:87-96. 2008.

Bodo M, Garcia A, Pearce F, vanAlbert S, Armonda R. Influence of volume and flow change on the electrical impedance signal (in vitro). J. Phys.: Conf. Ser. 224 012111 doi: 10.1088/1742-6596/224/1/0121112010.

Bodo M, Mahon R, Johnson I, Christy A, Rice RA, Hassan R, Slaughter T, Mikhalkevich Nadel A, Elster EA, McKay PL, Armonda RA, Popovic D. Study of cerebral blood flow autoregulation in rabbits. USUHS Research Days, 2014 May 14-15; poster 156.

Bodo M, Mahon R, Razumovsky A, Kouperberg E, Crimmins M, Armonda, Baruch M. Comparison of cerebrovascular reactivity tests: a pilot human study. J. Electr. Bioimp. 8, 25-33. https://doi.org/10.5617/ jeb.3939. 2017.

Bodo M, Montgomery LD, Pearce FJ, Armonda R. Measurement of cerebral blood flow autoregulation with rheoencephalography: a comparative pig study. J Electr Bioimp, vol. 9, pp. 123-132, https://doi.org/10.2478/ joeb-2018-0017 2018.

Bodo M, Nagy I, Peredi J, Thuroczy G, Ozsvald L, inventors; Process and equipment for diagnosing circulation (cerebrovascular) disorders. Hungarian patent P 9201 1079. 1992 Mar 31; International patent PCT/ HU 93/00006; PCT Pub. No: WO 93/19665. US patent, 5,584,297; Canada: CA 2133314. 1996.

Bodo M, Pearce F, Van Albert S, Armonda R. Rheoencephalogram reflects cerebral blood flow autoregulation in pigs. In: Hermann Scharfetter, Robert Merva (Eds.): ICEBI 2007, IFMBE (International Federation for Biomedical Engineering) Proceedings 17, pp. 695-698, www.springerlink.com (C) Springer-Verlag, Berlin Heidelberg, 2007.

Bodo M, Pearce FJ, Armonda RA. Cerebral blood flow changes: rat studies in rheoencephalography. Physiol Meas, 25 1371-1384. 2004.

Bodo M, Pearce FJ, Baranyi L, Armonda RA. Changes in the intracranial rheoencephalogram at lower limit of cerebral blood flow autoregulation. Physiol. Meas. 26 S1-S17. 2005

Bodo M, Pearce FJ, Montgomery LD, Rosenthal M, Kubinyi G, Thuroczy G, Braisted J, Forcino D, Morrissette C, Nagy I. Measurement of brain electrical impedance: animal studies in rheoencephalography. Aviat Space Environ Med 74:506-511. 2003.

Bodo M, Pearce, FJ, Tsai MCJ, Garcia A, vanAlbert S, Armonda R. Cessation of vital signs monitored during lethal hemorrhage: a swine study. J. Special Operations Medicine, 13/4: 63-75. 2013.

Bodo M, Peredi J, Karmos G, Bence J: On-line determination of cerebral blood flow by programmable calculator. Vth Hungarian Conference on Medical Electronics, Budapest, 272- 274, 1981.

Bodo M, Sheppard R, Hall A, Baruch M, Laird M, Tirumala S, Mahon R. Correlation of rheoencephalography and laser Doppler flow: a rat study. J Electr Bioimp, vol. 7, pp. 55-58. DOI: http:// dx.doi.org/10.5617/jeb.2985 2016.

Bodo M, Simovic M, Pearce F, Ahmed A, Armonda R. Correlation of rheoencephalogram and intracranial pressure: results of a rat study. Physiol. Meas. 36 N115N126. http://dx.doi.org/10.1088/0967-3334/36/10/N115 2015.

Bodo M, Szebeni J, Baranyi J, Savay S, Pearce FJ, Alving CR, Bünger R. Cerebrovascular involvement in liposome - induced cardiopulmonary distress in pigs. J. Liposome Res. 2005 15: 3-14.

Bodo M, Thuroczy G, Brockbank K, Sipos K. Cerebrovascular aging assessment by Cerberus. In: Klatz R, Goldman R. (eds) Anti-aging medical therapeutics, vol. II. Health Quest, Marina Del Rey, CA, 13:86-95. 1998.

Bodo M, Thuroczy G, Nagy I, Peredi J, Sipos K, Harcos P, Nagy Z, Voros J, Zoltai L, Ozsvald L: A complex cerebrovascular screening system. In: Lahtinen $\mathrm{T}$ (ed): Proceeding of the 8th International Conference on Electrical Bio-Impedance. July 28-31. Kuopio, Finland, 88-90, 1992.

Bodo M: Features of dynamics of rheoencephalographic parameters: experimental and clinical study. Ph.D. dissertation in Russian. IM Sechenov Institute of Evolutionary Physiology and Biochemistry, Academy of Sciences of the USSR, St. Petersburg; Hungarian Academy of Sciences, Budapest, 1990.

Bodo M. Studies in rheoencephalography (REG). J. Electr. Bioimp. 1:18-40. 2010.

Brady KM, Mytar JO, Kibler KK, Easley RB, Koehler RC, Czosnyka M, Smielewski, P, Zweifel C, Bodo M, 
Pearce FJ, Armonda RA. Monitoring cerebrovascular pressure reactivity with rheoencephalography. J. Phys.: Conf. Ser. $224 \quad 012089$ doi : 10.1088/1742-6596/224/1/012089, 2010.

Cannizzaro LA, Iwuchukwu I, Bodo M. Noninvasive Neuromonitoring with Rheoencephalography: A Pilot Human Study. Poster 71. NCS 17th Annual Meeting, October 15-18, 2019. Vancouver, British Columbia, CA https://www.neurocriticalcare.org/events/annualmeeting/ posters

Carney N, Totten AM, O'Reilly C, et al. Guidelines for the Management of Severe Traumatic Brain Injury, Fourth Edition. Neurosurgery. 80(1):6-15. doi:10.1227/ NEU.0000000000001432, 2017.

Christy A, Mahon R, Bodo M, Slaughter T, Mikhalkevich N, Johnson I, Nadel A, Elster EA, McKay PL, Armonda RA, Popovic D. Acetazolamide decreased end tidal CO2 in rabbits. USUHS Research Days, 2014 May 14-15; poster 151.

Czosnyka M, Czosnyka Z. Origin of intracranial pressure pulse waveform. Acta Neurochirurgica. June 13, https://link.springer.com/article/10.1007/ s00701-020-04424-4 2020.

Czosnyka M, Smielewski P, Kirkpatrick P, Laing RJ, Menon D, Pickard JD. Continuous assessment of the cerebral vasomotor reactivity in head injury. Neurosurgery 41:11-7. https://doi.org/ 10.1097/00006123-199707000-00005 1997.

de Freitas G, Bogousslavsky J. Primary stroke prevention. European J. Neurology 8:1-15. 2001.

Eniya GI. Rheography as method of evaluation of cerebral blood flow (in Russian). Riga: Zinatne, 1973. Naumenko AI, Skotnikov VV. Basics of Electroplethysmography (in Russian). Medicina, Leningrad. 1975.

Felbaum DR, Bodo M, Armonda R, McGowan JE, Christy AC, Elster E and Popovic D. Evaluation and validity between invasive and non-invasive cerebral blood flow autoregulation indices. Neuroscience Open House, Uniformed Services University of the Health Sciences, Bethesda, MD, Oct 29, 2015.

Felbaum DR, Bodo M, Armonda R, Ryan JE, Christy AC, Elster E, Popovic D. First experience of cerebral blood flow autoregulation index: a rabbit pilot study. Research Days, 2015, May 12-3, Uniformed Services
University of the Health Sciences, Bethesda, MD, May 12-3; poster $281 ; 2015$

Frohlich ED, Susic D. Blood pressure, large arteries, and atherosclerosis. Adv. Cardiol. 44:117-24. 2007.

Geddes LA, Hoff HE, Hall CW, Millar HD. Rheoencephalography. Cardiovasc Res Cent Bull. 44:112-22. 1964.

Gorelick PB. Stroke Prevention: An opportunity for efficient utilization of health care resources during the coming decade. Stroke, 25: 220-224. 1994.

Guyton AC. Textbook of medical physiology, 8th ed. Saunders, Philadelphia, 1991.

Hadjiev D. A new method for quantitative evaluation of cerebral blood flow by rheoencephalography. Brain Res 8:213-215. 1968.

Heilig J, Thuroczy G, Bodo M, authors: Real time data display software: REDIREC. United States copyright, TXu 879 -647. 1998.

Hughson RL et al. Increased post-flight carotid artery stiffness and inflight insulin resistance resulting from 6mo spaceflight in male and female astronauts. Am. J. Physiol. Heart Circ. Physiol. 10:H628-638. doi:10.1152/ ajpheart.00802.2015.

ICG: https://www.biopac.com/application/icgimpedance-cardiographycardiac-output/

ICM. https://www.biopac.com/application/icgimpedance-cardiographycardiac-output/

Iwasaki $\mathrm{K}$ et al. Human cerebral autoregulation before, during and after spaceflight. PMID: 17185344 P M C I : P M C 2151354 D O : 10.1113 / jphysiol.2006.1196362007.

Jacquy J, Dekonick WJ, Piraux A, Calay R, Bacq J, Levy D, Noel G. Cerebral blood flow and quantitative rheoencephalography. Electroenceph Clin. Neurophysiol 37:501-511. 1974.

Jenkner FL. Clinical rheoencephalography: a noninvasive method for automatic evaluation of cerebral hemodynamics, Vienna (A) Ertldruck; 1986.

Jenkner FL. Rheoencephalographic differentiation of vascular headaches of varying causes. Markovich SE (ed): Annals of the New York Academy of Sciences, Vol 
170, Article 2, Pages 407-836. International Conference on Bioelectrical Impedance. 1970.

Kabakcioglu M, Douligeris C, Bodo M, Thuroczy G: Application of machine learning and expert system methods for automated cerebrovascular screening. 2nd Hungarian Stroke Conference, Debrecen, Dec. 1-3. Poster \# 46. 1994.

Kermorgant M, Nasr N, Czosnyka M, Arvanitis DN, Hélissen O, Senard J-M and Pavy-Le Traon A. Impacts of Microgravity Analogs to Spaceflight on Cerebral Autoregulation. Front. Physiol. 11:778. doi: 10.3389/ fphys.2020.00778 2020 .

Klein T, Wollseiffen P, Sanders M, Claassen J, Carnahan H, Abeln V, Vogt T, Strüder HK, Schneider S. The influence of microgravity on cerebral blood flow and electrocortical activity. Exp Brain Res. 237(4):1057-1062. doi: 10.1007/s00221-019-05490-6. PMID: 30741333. 2019.

Kontos HA et al. Responses of cerebral arteries and arterioles to acute hypotension and hypertension. Am. J. Physiol. 234:H371-83. 1978.

Kubicek et al. Impedance plethysmograph. United States Patent RE30101. 1975.

Kubicek WG, Kottke FJ, Ramos MU et al. The Minnesota impedance cardiograph - theory and applications. Bio-Medical Engineering, 9(9): 410-416, PMID: 4416602, 1974.

Law et al. Relationship Between Carbon Dioxide Levels and Reported Headaches on the International Space Station. J. Occup. Environ. Med. 56(5):477-83 DOI: 10.1097/JOM.00000000000001582014.

Lifshitz K. Rheoencephalography. I. Review of the technique. J. Nerv. Ment. Dis.136:388-98. 1963.

Lifshitz K. Rheoencephalography. II. Survey of clinical applications. J. Nerv. Ment. Dis. 137:285-96. 1963.

Maltron International Ltd, https://maltronint.com/ Accessed 7/8/2020

Mancini GBJ. Angiographic assessment of atherosclerosis progression and regression. Woodford FP, Davignon J, Sniderman A (eds.). Atherosclerosis X. Amsterdam: Elsevier; pp. 984-988. 1995
Markovich S, Scheinberg P, Shafey S, Namon R, Sano R. Clinical monopolar rheoencephalography. J. Neurol. Sci. 5:267-72. 1967.

Markus HS, Brainin M. COVID-19 and stroke-A global World Stroke Organization perspective. Int. J. Stroke. $2020 \quad$ Jun; $15(4): 361-364$ d o i : 10.1177/1747493020923472. PMID: 32310017. 2020.

Mausner JS, Kramer S. Mausner and Bahn Epidemiology - An introductory text. Philadelphia: WB Saunders; pp. 1-42. 1985.

McDonald K. The case of the fainting astronaut. Australian Life Scientist. Jan/Feb, p 50-60. 2009.

McHenry LC. Rheoencephalography: a clinical appraisal. Neurology. 15:507-17. 1965 https://doi.org/ 10.1212/WNL.15.6.507

Medis, https://medis.company/cms/index.php Accessed $7 / 8 / 2020$

Meghdadi AH, Popovic D, Rupp G, Smith S, Berka C, Verma A. Transcranial Impedance Changes during Sleep: A Rheoencephalography Study. IEEE J Transl Eng Health Med. 2019; 7:2700107. doi:10.1109/ JTEHM.2019.2898193. 2019.

Montgomery LD et al. An impedance device for study of multisegmented hemodynamic changes during orthostatic stress. Aviat Space Environ Med 60:1116-22. 1989.

Moskalenko YE. (ed) Biophysical Aspects of Cerebral Circulation. Oxford: Pergamon, 1980.

Nagy I, Bodo M, Thuroczy G, authors. GRAL: Highlevel interactive graphical language for signal processing. United States copyright TXu 1-025-933. 2001.

Namon R, Gollan F, Shimojyo S, Sano RM, Markovich SE, Scheinberg P. Basic studies in rheoencephalography. Neurology. 17:239-52. 1967.

NCS. Neurocritical Care Society web site: https:// www.neurocriticalcare.org/resources/guidelines

Nyboer J, Electrical Impedance Plethysmography, Charles C. Thomas, Spfld. IL, pp. 50-57. 1954.

Nyboer J. Regional pulse volume and perfusion flow measurement. AMA Arch Internat Med 105: 264-76. 1960. 
Nyboyer J. Electrorheometric properties of tissues and fluids. In: International Conference on Bioelectrical Impedance. Ed.: Markovich SE Annals of the New York Academy of Sciences 170, New York. NY pp. 410-420. 1970 .

Patterson R. Bioelectric impedance measurement. In: The Biomedical Engineering Handbook. Bronzino JD (ed), CRC Press, Boca Raton, pp. 1223-1230. 1995.

Peredi J, Bodo M, Csakany A: Measuring, data processing and tape-recording units in TDC system. 7th Hungarian Conference on Biomedical. Eng. Esztergom, HU, 16-18 Sept, 237-239, 1987.

Peredi J, Karmos G, Bencze J, Bodo M, inventors; Block scheme for feeding of electric signals into digital calculator. Hungarian patent 183,350, Category: NSZO3 G 06F 3/02. 1981.

Perez JJ. To what extent is the bipolar rheoencephalographic signal contaminated by scalp blood flow? A clinical study to quantify its extra and non-extracranial components Biomed. Eng. Online 13 131. 2014

Perez-Borja C, Meyer JS. A critical evaluation of rheoencephalography in control subjects and in proven cases of cerebrovascular disease. J. Neurol. Neurosurg. Psychiatr. 27:66-72. 1964

Polzer K, Schuhfried F. [Development and technic of rheography.] Wien Med Wochenschr. 112:153-5. [Article in German] 1962.

Popovic D, Bodo M, Pearce F, van Albert S, Garcia A, Settle T, Armonda R. Assessment of cerebral blood flow autoregulation (CBF AR) with rheoencephalography (REG): studies in animals. J. Phys.: Conf. Ser. 434. 012042 doi:10.1088/1742-6596/434/1/012042 2013.

Ringelstein EB, Van Eyck S, Mertens I. Evaluation of cerebral vasomotor reactivity by various vasodilating stimuli: comparison of $\mathrm{CO} 2$ to acetazolamide. J. Cereb. Blood Flow Metab. 12:162-8. https:// journals.sagepub.com/doi/10.1038/jcbfm.1992.201992.

Rubin M, Yo M, Agostini MA, Madden J, Diaz-Arrastia RR. Noninvasive Monitoring. In: Jallo J, Loftus CM (eds). Neurotrauma and critical care of the brain, Thieme, New York, 2009.
Seipel JH. The biophysical basis and clinical applications of rheoencephalography. Neurology. 17:443-51. 1967.

Sipos K, Bodo M, May Z, Lendvai B, Piros A, Spitzer N, Pataky I, Nagy Z, Banyasz A. Risk of mental disorders, their changes and somatic consideration in rural Hungary. Ideggyogy. Sz. 61(3-4):97-105. 2008.

Sipos K, Bodo M. Anxiety, and cerebrovascular status in Hungarian population. In: Stress and Anxiety; Contributions of the STAR Award Winners. Eds: Buchwald P, Moore KA, Kaniasty K, Arenas-Landgrave P. Chapter 4. pp 39-50. Logos Verlag, Berlin. ISBN: 978-3-8325-4934-3. 2019.

Sokolova IV, Iarullin HH: System of automatic analysis of rheoencephalograms. Kosm. Biol. Aviakosm. Med. 16, 81-83 1982 .

Sokolova IV, Yarullin HH, Maksimenko IM, Ronkin MA. Analysis of the structure of rheoencephalogram as a pulse filling of blood (in Russian) J. Nevropathol 77:1314- 1321. 1977

Strandgaard S, Paulson OB. Cerebral autoregulation. Stroke. 15(3):413-6. 1984.

Szalay P, Sipos K, Szucs L, Bodo M, Sowd M, Pearce FJ. REG can be used to detect cerebrovascular alteration caused by alcoholism. Acta Physiol Hung, 93:117-130. 2006

Taylor CR, Hanna M, et al. Spaceflight-induced alterations in cerebral artery vasoconstrictor, mechanical, and structural properties: implications for elevated cerebral perfusion and intracranial pressure. FASEB J. 27(6):2282-92. doi: 10.1096/fj.12-222687. PMID: 234572152013.

Thuroczy G, Bodo M, Kubinyi G, Bakos J, Szabo LD. Rheoencephalogram and EEG activity increasing after microwave exposure on rats. In: Lahtinen $\mathrm{T}$ (ed): Proceeding of the 8th International Conference on Electrical Bio-Impedance. July 28-31. Kuopio, Finland, 92-94, 1992

Thuróczy G, Kubinyi G, Sinay H, Bakos J, Sipos K, Lenart A, Szabo LD. Human electrophysiological studies on influence of RF exposure emitted by GSM cellular phones. In: Bersani, F (ed). Electricity and magnetism in biology and medicine: Proceedings of the Second World Congress for Electricity and Magnetism in Biology and Medicine, June 8-13, 1997, in Bologna, Italy. New York (NY), Plenum Press, pp. 721-724. 1999. 
Traczewski W, Moskala M, Kruk D, Gościński I, Szwabowska D, Polak J, Wielgosz K. The role of computerized rheoencephalography in the assessment of normal pressure hydrocephalus. J Neurotrauma. 22(7):836-43. doi:10.1089/neu.2005.22.836. PMID: 16004585. 2005.

Trejo-Gabriel-Galán JM. Stroke as a complication and prognostic factor of COVID-19. Neurologia. 2020 Jun;35(5):318-322. English, Spanish. doi:10.1016/ j.nrl.2020.04.015. PMID: 32493597. 2020.

UFI, http://ufiservingscience.com/index.html Accessed $7 / 8 / 2020$

Waltz AG, Ray CD. Impedance cephalography ("rheoencephalography"). Trans Am Neurol Assoc. 90:305-7. 1965.

Wa ltz A G, Ray C D. In a d e quacy of "rheoencephalography". A clinical study of impedance cephalography for evaluation of cerebrovascular disorders. Arch. Neurol. 1967; 16:94-102. 1967

Weinstein GB et al. Automated rheoencephalogram analysis. Fiziol. Zh. SSSR Im. I. M. Sechenova. 64, 564-567 1978.

WHO Key facts - cardiovascular diseases

Windkessel effect https://en.wikipedia.org/wiki/ Windkessel_effect (Accessed 7/8/2020).

Yarullin HH. Clinical rheoencephalography. (In Russian) Leningrad: Medicina; 1965.

Yatsu FM, Fischer M. Atherosclerosis: current concepts on pathogenesis and interventional therapies. Ann Neurol 26:3. 1989.

Yegorov AD. Results of medical studies during longterm manned flights on the orbital Salyut 6 and Soyuz complex. NASA TM 76014. 1979.

Zoltai L, Bodo M, Pasztor I: Two types of rheograph for multipurpose measurement. 7th Hungarian Conference on Biomedical Eng. Esztergom, HU. 16-18 Sept, 63-65, 1987.

Zuj KA, et al. Impaired cerebrovascular autoregulation and reduced $\mathrm{CO}_{2}$ reactivity after long duration spaceflight. Am. J. Physiol. Heart Circ. Physiol. 302:H2592-8. doi.org/10.1152/ajpheart.00029. 2012. 